\title{
Sturge-Weber Syndrome - Clinical Case Study
}

\author{
Sirakova K ${ }^{1}$, Minkin K. ${ }^{2}$, Matanov Sv. ${ }^{3}$, Ninov K. ${ }^{4}$ \\ UH "St. IvanRilski”
}

\begin{abstract}
Sturge-Weber syndrome (SWS) or encephelotrigeminal angiomatosis is a syndrome, characterized by local brain atrophy and calcifications in the cerebral cortex combined with ipsilateral "Port Wine" facial nevus in the area innervated by the nervus trigeminus. SWS is a rare syndrome having incidence of 1 in 20.000-50.000 people. It affects men and women equally. SWS is a sporadically occurring congenital malformation and the fetal cortical veins (during 4-8 gestational week) develop abnormality, i.e. they remain "fetal". There is no evidence of hereditary transmission. As associated gene mutation was found in nucleotide transition in GNAQ on chromosome 9q21. The venous drainage from the superficial brain part is carried out through sinus sagitalis superior, and the deep veins - through sinus cavernosus and straight sinus. Cortical veins serve as a liaison between the two vein systems that flow in an internal jugular vein
\end{abstract}

Keywords: Sturge-Weber syndrome, epilepsy

\section{Introduction}

Sturge-Weber syndrome (SWS) or encephelotrigeminal angiomatosis is a syndrome, characterized by local brain atrophy and calcifications in the cerebral cortex combined with ipsilateral "Port Wine" facial nevus in the area innervated by the nervus trigeminus.

SWS is a rare syndrome having incidence of 1 in 20.00050.000 people. It affects men and women equally. SWS is a sporadically occurring congenital malformation and the fetal cortical veins (during 4-8 gestational week) develop abnormality, i.e. they remain "fetal". There is no evidence of hereditary transmission. As associated gene mutation was found in nucleotide transition in GNAQ on chromosome $9 \mathrm{q} 21$.

The venous drainage from the superficial brain part is carried out through sinus sagitalis superior, and the deep veins - through sinus cavernosus and straight sinus. Cortical veins serve as a liaison between the two vein systems that flow in an internal jugular vein

InSWS thecortical "connecting" veins are dysplastic and the normal venous drainage is disrupted, where at the available veins are "overfilled" and the blood flow in them is bidirectional. Blood can now be returned into the superficial veins (leptomeningeal, facial) or deep vein/sinuses. This inturnis a prerequisite for venousthrombosis formation with subsequent deposition of calcium and loss of nerve cells.

The clinical manifestation in SWS can be found at birth by the presence of facial angioma along the nervus trigeminus (in14\% of the patients cutaneous angiomamay not be present). Theocular manifestation of the syndrome is the presence of choroidalorscleralangiomas, which inturn causes increased intraocular pressure that is expressed with congenitalglaucoma. Concerning the central nervous system seizures are most expressed (70-90\%), then hemiparesis $(30-66 \%)$, "stroke-like "episodes, and developmental delays.

\section{Clinical Case}

We present you the child H.H. at the age of 10, having severe pharmacoresistant epilepsy since he was 3 months old, that cannot be controlled by the administered antiepileptic drugs in various combinations. The partial motor seizures were expressed as clonic seizures by the right limbs accompanied by speech blockage and fear. Partial onset seizure frequency was 3-4 times a week, and secondarily generalized seizures emerged once a week.The child was diagnosed with Sturge-Weber syndrome capillary hemangioma (nevus flameus) affecting the left facial half and scalp, cognitive deficits (IQ = 51) and severe right-sided hemiparesis.

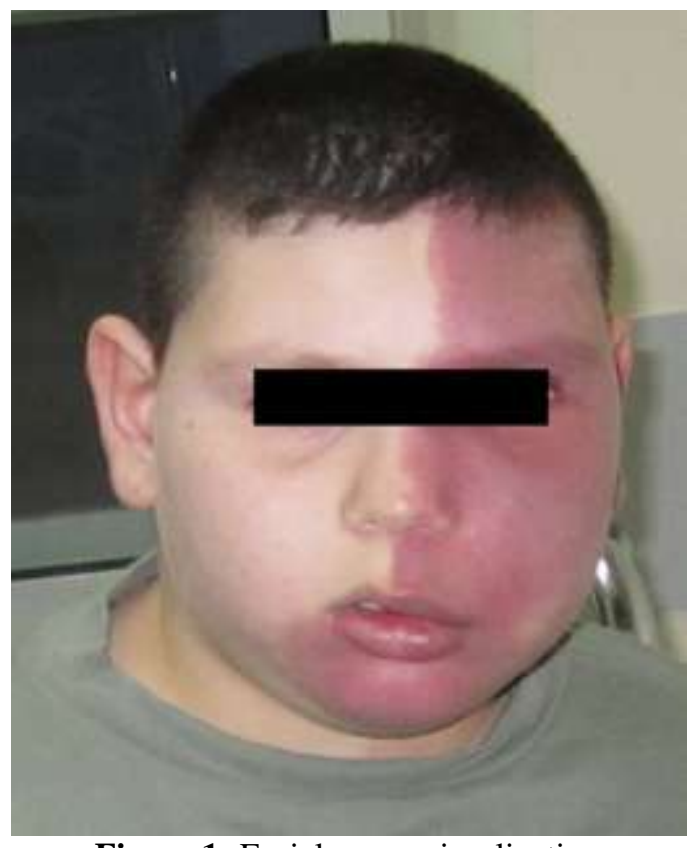

Figure 1: Facial nevus visualization

During the imaging diagnostic with native CT scan an expressed brain atrophy at the left andfrontoparieto with massive calcification at the convexity was visualized. 


\section{International Journal of Science and Research (IJSR) \\ ISSN (Online): 2319-7064}

Index Copernicus Value (2016): 79.57 | Impact Factor (2015): 6.391
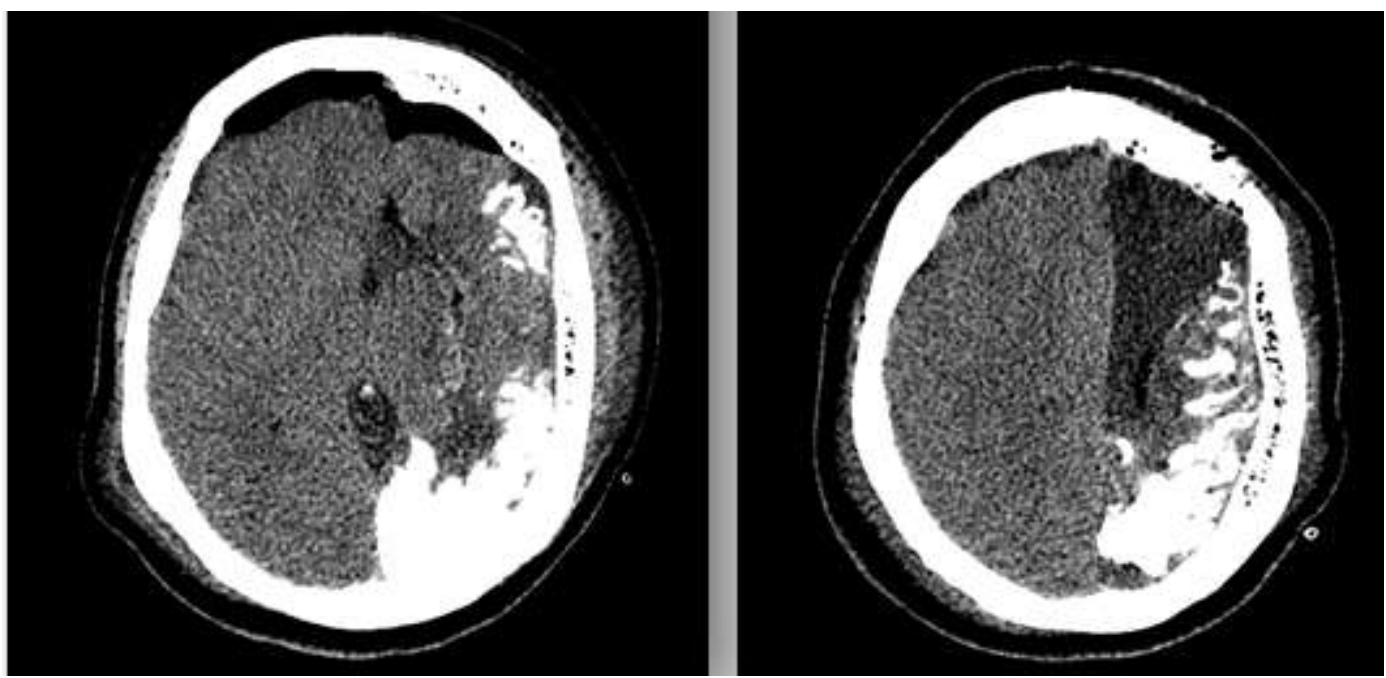

Figure 2a \& 2b: Native CT, imaging numerous calcifications in the atrophic cortex on the left

Subsequently, MRI examination was performed, which confirmed the expressed brain atrophy and parenchyma at the left, and decreased signal intensity of the white brain matter.
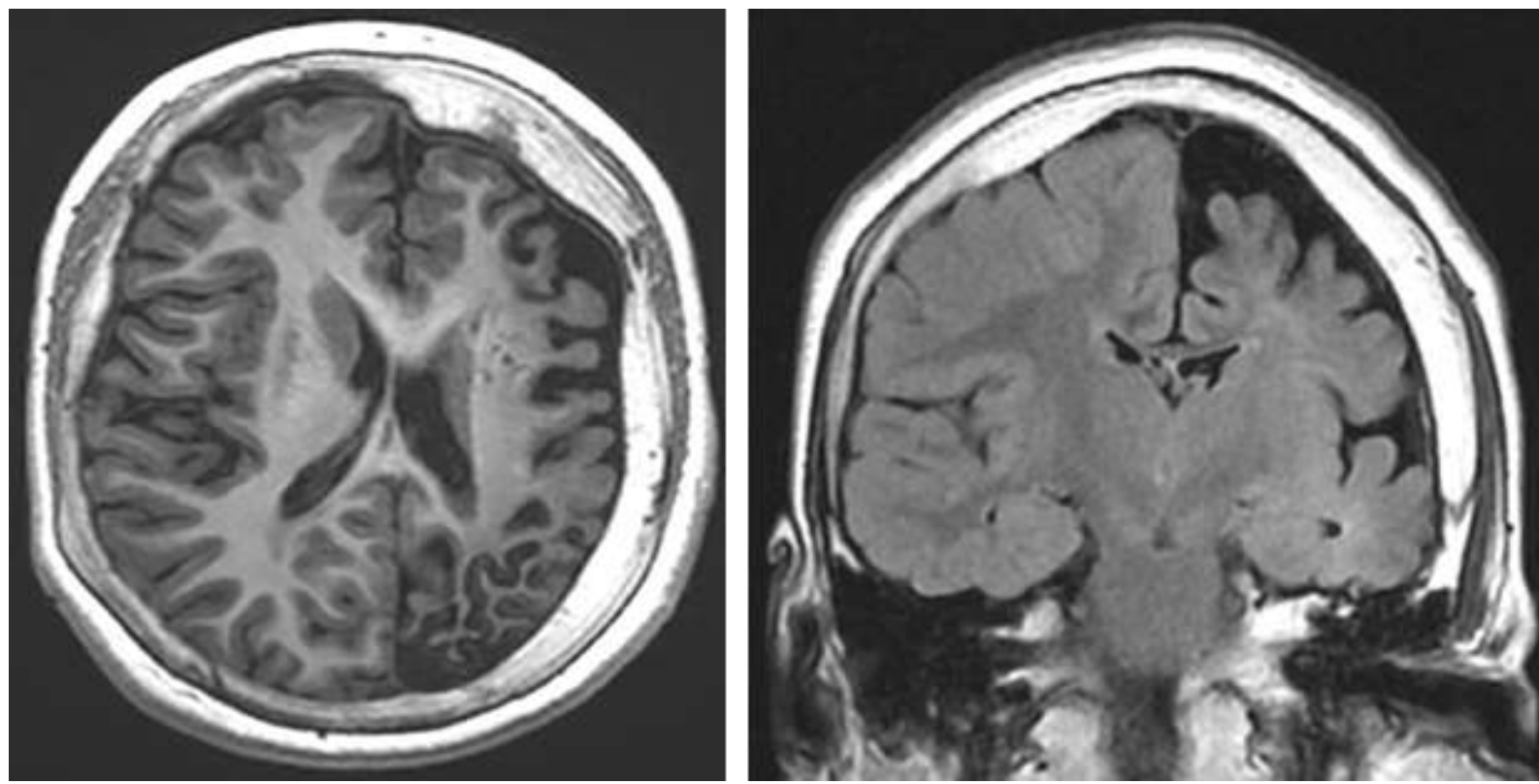

Figure 3a \& 3b: MRI imaging the expressed brain atrophy of the left brain hemisphere

The performed Wadatest found out, that the right hemisphere is dominant for speech and the right-sided hemiparesis is not exacerbated during the functional blocking of the left hemisphere.

After a multidisciplinary discussion it was decided that the child is indicated for left hemispherotomy. A parasagital vertical hemispherotomy by Delalande was performed and as second stage it was needed to place a lumbar-peritoneal anastomos is due to the development of communicating hydrocephalus. After the hemispherotomy the child has no epileptic seizures, without aggravation of the preoperative neurological deficit and with improved cognitive deficits as the follow-up period is 2 years.

Volume 6 Issue 12, December 2017 www.ijsr.net 


\section{International Journal of Science and Research (IJSR) \\ ISSN (Online): 2319-7064}

Index Copernicus Value (2016): 79.57 | Impact Factor (2015): 6.391
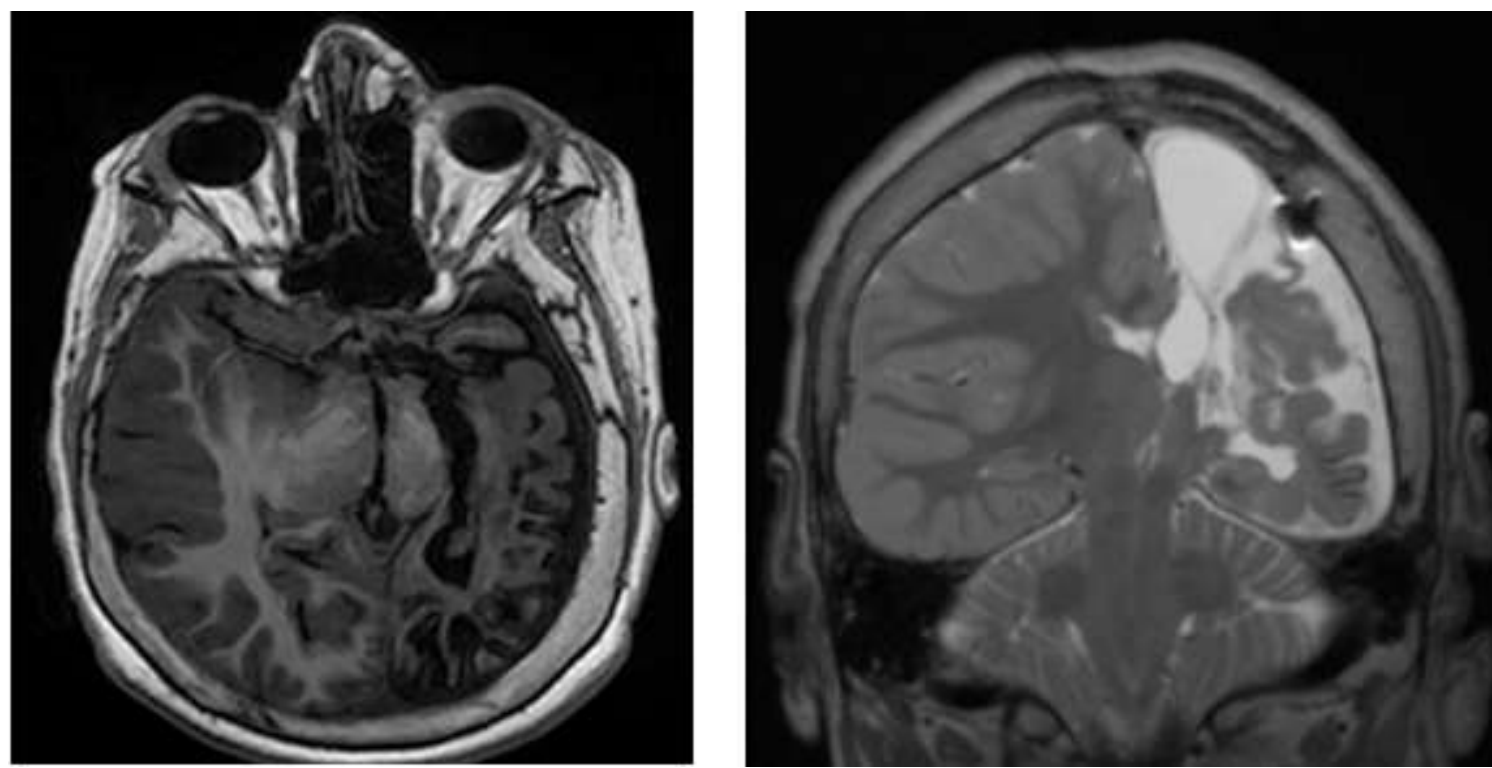

Figure 4a \& 4b: MRI after the hemispherotomy imaging the postoperative changes in the performed operative intervention area on the left

\section{Discussion}

The case presented in this publication is the first hemispherotomy performed in Bulgaria.

Hemispherotomies are one of the most successful interventions in relation to the epilepticseizures control. Delalandereports about full control over seizures in $74 \%$ of the cases (60 patients in a series of 83 patients). These interventions have the greatest potential to successfully discontinue the antiepileptic drugs administration $-77 \%$ of the patients have achieved full control over the epilepticseizures.

The performed imaging examinations as CT, MRI and WADA test are essential when choosing the therapy and the preoperative surgical planning.

SWS is a rare syndrome with a high degree of lobar involvement and cerebral atrophy leading to severe pharmaco resistant epilepsy. For their part, seizures cause further brain damage with progressing hemiparesis. Hemispherotomies are an important part of the neurosurgical interventions range that can significantly improve the severe pharmaco resistant epilepsies control.

\section{Conclusion}

The imaging examinations as CT and MRI contribute to the correct diagnosis and treatment regimen determination for the treatment of patients with SWS. Also, they take an integral part in the treatment and follow-up throughout the postoperative period.

\section{References}

[1] Dandy WE. Removal of right cerebral hemisphere for certain tumors with hemiplegia: preliminaryreport. JAMA, 1928, 90:823-25.

[2] SirakovS., KamenovB., PenkovM., Marinov M. Double lumenballooncatheterinarterio-venousmal formation embolization using Onyx Roentgenologia \& Radiologia, 2015, LIV: 122-125

[3] SirakovS., KamenovB., PenkovM., MarinovM. Clinicalcase of a complex arteriovenousmal formation. Bulg Neurosurg, 2014 ,19 (1-2)

[4] Lhermitte J. Ultimate results of hemispherectomy in cases of infantile cerebral hemiatrophy productive of epilepsy [inFrench]. Encéphale, 1928, 23:314-23.

[5] SirakovS. Arterio-venousmal formation - classification, imaging and endovascular treatment. Roentgenologia \& Radiologia, 2015, LIV:86-96

[6] Krynauw RA: Infantile hemiplegia treated by removing one cerebral hemisphere. J Neurol Neurosurg Psychiatry, 1950, 13:243-67.

[7] Sirakov S., BuchvarovCh. , PenkovM., SirakovA., KamenovB., TodorovY., Ninov K., Transvenous embolization of indirect carotid-cavernous fistula via upper ophthalmic/facialvein - case report and literature review. Roentgenologia \& Radiologia, 2015, LIV : 242246

[8] Rasmussen T: Hemispherectomyforseizuresrevisited. Can J NeurolSci, 1983, 10:71-78.

[9] Sirakov S. , Penkov M. , Sirakov A. , Minkin K. , Ninov K. Preoperative Embolization of Hemangioblastomas International Journal of Science andResearch (IJSR), Volume 6 Issue 1, January 2017 , ISSN (Online): 2319-7064

[10] Sparrow SS, Cicchetti DV. Diagnosticuses of theVineland Adaptive Behavior Scale. J Pediatr Psychol, 1985, 10(2), 215-25.

[11] Sirakov S. , Popivanov P. , Sirakov A. , Sirakova K. Endovascular Embolisation of a Complex Arteriovenous Malformation International Journal of Science and Research (IJSR), Volume 6 Issue 4, April 2017 , ISSN (Online): 2319-7064

[12] Villemure JG, Mascott CR: Peri-insular hemispherotomy: Surgicalprinciplesandanatomy. Neurosurg, 1995, 37:975- 81.

[13] Sirakov S., Sirakov A. , Minkin K. Endovascular Embolization of High-Risk Arteriovenous Malformation. International Journal of Science and

\section{Volume 6 Issue 12, December 2017}




\section{International Journal of Science and Research (IJSR) \\ ISSN (Online): 2319-7064}

Index Copernicus Value (2016): 79.57 | Impact Factor (2015): 6.391

Research (IJSR), Volume 6 Issue 2, February 2017 , ISSN (Online): 1437-1441

[14] Wyllie E, Gupta A, Lachhwani DK. Thetreatment of epilepsy, principles\&practice. Lippincott Williams \& Wilkins. (2006) ISBN:0781749956. Readitat Google Books - FinditatAmazon

[15] Sirakov S. Kamenov B. , Penkov M. , Romansky K. Internal carotidarteryblisteraneurysmembolization Roentgenologia \& Radiologia 2015 , LIV: 184-186,

[16] Hay WW, Hayward AR, Levin MJ et-al. Current pediatric diagnosis \& treatment. McGrawHill/Appleton\& Lange. (2002) ISBN:0071383840. Readitat GoogleBooks - FinditatAmazon

[17] Sirakov S. , Sirakov A., Preoperative endovascular embolization of juvenile nasopharyngeal angiofibroma International Journal of Science and Research (IJSR), Volume 6 Issue 2, February 2017 , ISSN (Online): 1434-1436

[18] Moore GJ, Slovis TL, Chugani HT. Protonmagnetic resonance spectroscopy in children with Sturge-Weber syndrome. J.ChildNeurol. 1998;13 (7): 3325. doi:10.1177/088307389801300705 - Pubmedcitation

[19] Sirakov S., Hristov H., Sirakov A. , Ninov K. Endovascular Embolization of a Spinal Arteriovenous Fistula International Journal of Science and Research (IJSR), Volume 6 Issue 2, February 2017 , ISSN (Online): 1216-1220 